\title{
Production of Biogas Using Dairy Manure as Feedstock and Rumen Fluid as Inoculum
}

\author{
Shanti Faridah Salleh ${ }^{1, *}$, Muhammad Hifzhan Amsyar Zulkifli ${ }^{2}$ and Mohd Rahmat Jalani ${ }^{3}$ \\ 1,2,3Faculty of Engineering, Universiti Malaysia Sarawak, 94300 Kota Samarahan,Malaysia.
}

\begin{abstract}
Methane gas is a valuable gas that can be used as a source of energy, either used for cooking fuel or small-scale electricity production. The most suitable application of the methane gas is in rural areas which rarely have the source of energy. It can reduce the dependency of using diesel or gasoline in order to obtain electricity. This study focused on the use of dairy manure as the feedstock and the rumen fluid as the innoculant to improve the production of biogas in rural areas application. The amount of rumen fluid and water added were varied to prepare $0 \%, 12.5 \%, 25 \%, 37.5 \%$ and $50 \%$ rumen fluid. Besides that, the pH level was monitored and its effects towards biogas production was discussed. From the experiment, sample with $37.5 \%$ rumen fluid gave the highest biogas production, followed by $50 \%, 25 \%, 12.5 \%$ and $0 \%$ rumen fluid. The presence Rumen fluids have improved the biogas production for the anaerobic digestion.
\end{abstract}

Keywords: Anaerobic digestion, biogas, rumen fluid, manure

\section{Introduction}

There are two different sources of energy production, which are non-renewable and renewable. The energy production slowly is changing its focus to the renewable energy which is more green. Energy is the most important in human daily life as the source of electricity and the challanges that have been critical in this modern age is to meet the rapid increment of energy demand for the citizen. The challenge also comes in supplying the electricity to rural areas with difficult routes of communication and development. Table 1 shows the electricity supply to the rural area by state in Malaysia.

This electricity supply in Malaysia is mostly contributed from oil, natural gas and coal power generation which is non-renewable energy source. From Table 1, the lowest electric supply to the rural area is Sarawak followed by Sabah with $66.91 \%$ and $67.05 \%$ respectively. Sabah and Sarawak are one of the largest area states in Malaysia where most of the rural area is uncovered with modern technology. Rural areas are lived by various ethnics who are not exposed to the real world due to distance and transportation constraint. In Sarawak, most of the rural areas are located in deep forest and at high mountain. These problems have caused difficulties in construsting grid lines to supply electricity to the specific area.

As alternative, biogas energy which is categorized as renewable energy can be used as the power generation in the rural areas. The term biogas is referring to gas which is produced by the biological breakdown of organic matter in the absence of oxygen [2].

\footnotetext{
* Corresponding author

E-mail address: shanti_faridah@yahoo.com
}

Manuscript History:

Received 4 August, 2016, Revised 21 September, 2016, Accepted 23 September, 2016, Published 30 September, 2016

e-ISSN 2289-7771

Copyright (C) 2016 JASPE 
Table 1: Electricity supply in rural area by state in Malaysia [1]

\begin{tabular}{|l|l|}
\hline State & Electrity supply (\%) \\
\hline Johor & 98.22 \\
\hline Kedah & 98.58 \\
\hline Kelantan & 97.50 \\
\hline Melaka & 99.28 \\
\hline N. Sembilan & 98.60 \\
\hline Pahang & 93.96 \\
\hline Perak & 96.11 \\
\hline Perlis & 99.17 \\
\hline P.Pinang & 99.16 \\
\hline Sabah & 67.05 \\
\hline Sarawak & 66.91 \\
\hline Selangor & 97.92 \\
\hline Terengganu & 98.24 \\
\hline W.P. Kuala Lumpur & - \\
\hline
\end{tabular}

According to NRDC (n.d.), biogas that is produced contains majorly $60 \%$ - $70 \%$ of methane gas that can generate heat, hot water or electricity and the effluent can be used as fertilizer, while the other 30\%-40\% is carbon dioxide and some other traces gases. This process which does not consume oxygen is known as anaerobic digestion that is done by the microbes present in the animal wastes. Table 2 shows the gas component and its amount present in biogas.

Table 2: Types of gases and its amount in biogas. [2]

\begin{tabular}{|c|c|}
\hline Components & Amount (\%) \\
\hline Methane & $50-75$ \\
\hline Carbon dioxide & $25-45$ \\
\hline Water vapour & $2-7$ \\
\hline Sulphide & $0.002-2$ \\
\hline Nitrogen & $<2$ \\
\hline Ammonia & $<1$ \\
\hline Hydrogen & $<1$ \\
\hline Traces gases & $<2$ \\
\hline
\end{tabular}

\section{Methodology}

In this experiment, two different feedstock which were dairy manure and rumen fluid were collected from the dairy house loacated at Kampung Assum, Padawan, Sarawak. The sample is kept and transported in a dry Coleman ${ }^{\mathrm{TM}}$ cooler and stored in a cold room at ${ }^{\circ} \mathrm{C}$. While transferring the sample back to the lab, the sample was not be exposed to any extreme temperature conditions and contacting with huge amount of water by because it might disturb the microbial activities within the feedstock (El-Mashad, 2004).

Rumen fluid was prepared by filtration process using filter cloth to separate solid content from the slurry. Next, high quantity of bacteria was obtained by filtering the solution with 10 micron cartridge. Raw dairy manure was stirred to assure its homogeneity. The procedure for the experiment 
was divided into two different categories which is existing anaerobic digester and fabricated anaerobic digester.

In the existing anaerobic digester, $5 \mathrm{~kg}$ of dairy manure is weighted using measuring balance and fed into the feed tank. Next, distilled water was added to the digester with ratio of (M:W) 1:0.25, corresponding to $0 \%$ rumen fluid. The mixture was stirred using propeller and manually. The $\mathrm{pH}$ level of the sample was measured using $\mathrm{pH}$ meter and recorded. Nitrogen gas was passed through to the reactor to ensure the anaerobic process (Budiyono et al., 2009; Budiyono et al., 2010). The temperature was set at $35^{\circ} \mathrm{C}$ under mesophilic condition using the temperature controller that installed together with the digester. The production of biogas from the anaerobic digestion was recorded with hydraulic retention time of 40 days.

In the fabricated anaerobic digester, $1 \mathrm{~kg}$ of dairy manure was weighted and fed into feed tank. After that, $250 \mathrm{~g}$ of distilled water is mixed together with dairy manure, creating ratio of (M: W: R) 1:0.25:0 which correspond to $0 \%$ of rumen fluid. The $\mathrm{pH}$ level of the feedstock was taken and measured initially an at the end of experiment. An eggshell was used to maintain the $\mathrm{pH}$ of the experiment.To ensure the process was anaerobic digestion, nitrogen gas was passed through the fabricated biodigester. The heat in this biodigester unit is supplied by a series of bulbs and the temperature was monitored by a thermometer to make sure the process was mesophilic conditions. The biogas production is then recorded daily with hydraulic retention time of 40 days. The procedure is repeated in other four different biodigester by varying the amount of distilled water and rumen fluid as presented in Table 3 .

Table 3: Amount of cow manure, water and rumen fluid in each biodigester.

\begin{tabular}{|c|c|c|c|}
\hline Biodigester Unit & Cow manure (g) & Water (g) & $\begin{array}{c}\text { Rumen Fluid (g) } \\
(\boldsymbol{\%})\end{array}$ \\
\hline 1 & 1000 & 250 & 0 \\
\hline 2 & 1000 & 750 & 12.5 \\
\hline 3 & 1000 & 500 & 25 \\
\hline 4 & 1000 & 250 & 27.5 \\
\hline 5 & 1000 & 0 & 50 \\
\hline
\end{tabular}

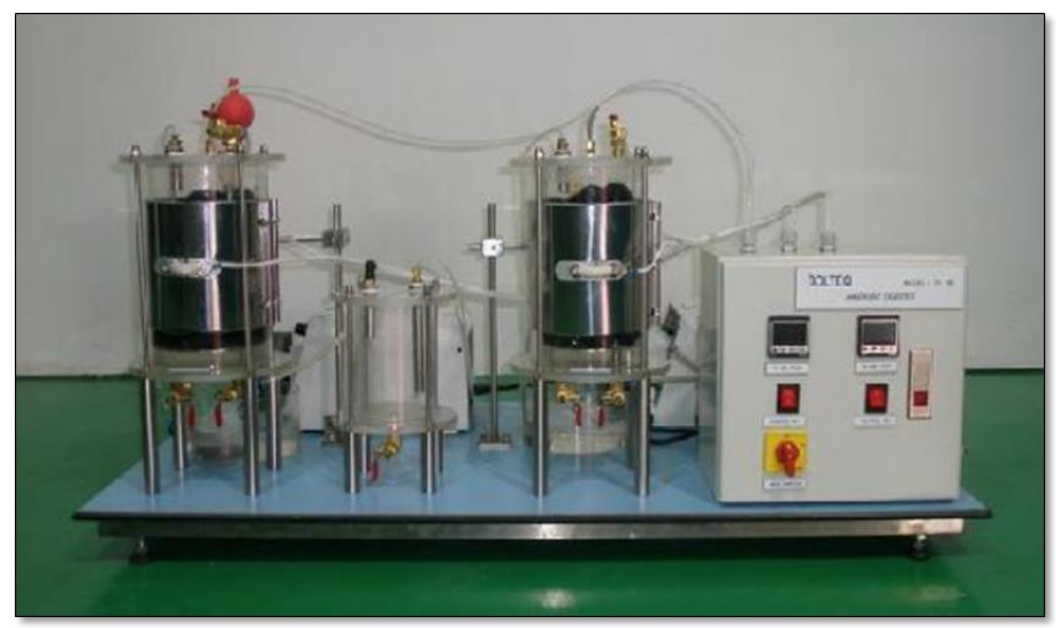

Figure 1: Existing biodigester unit. 


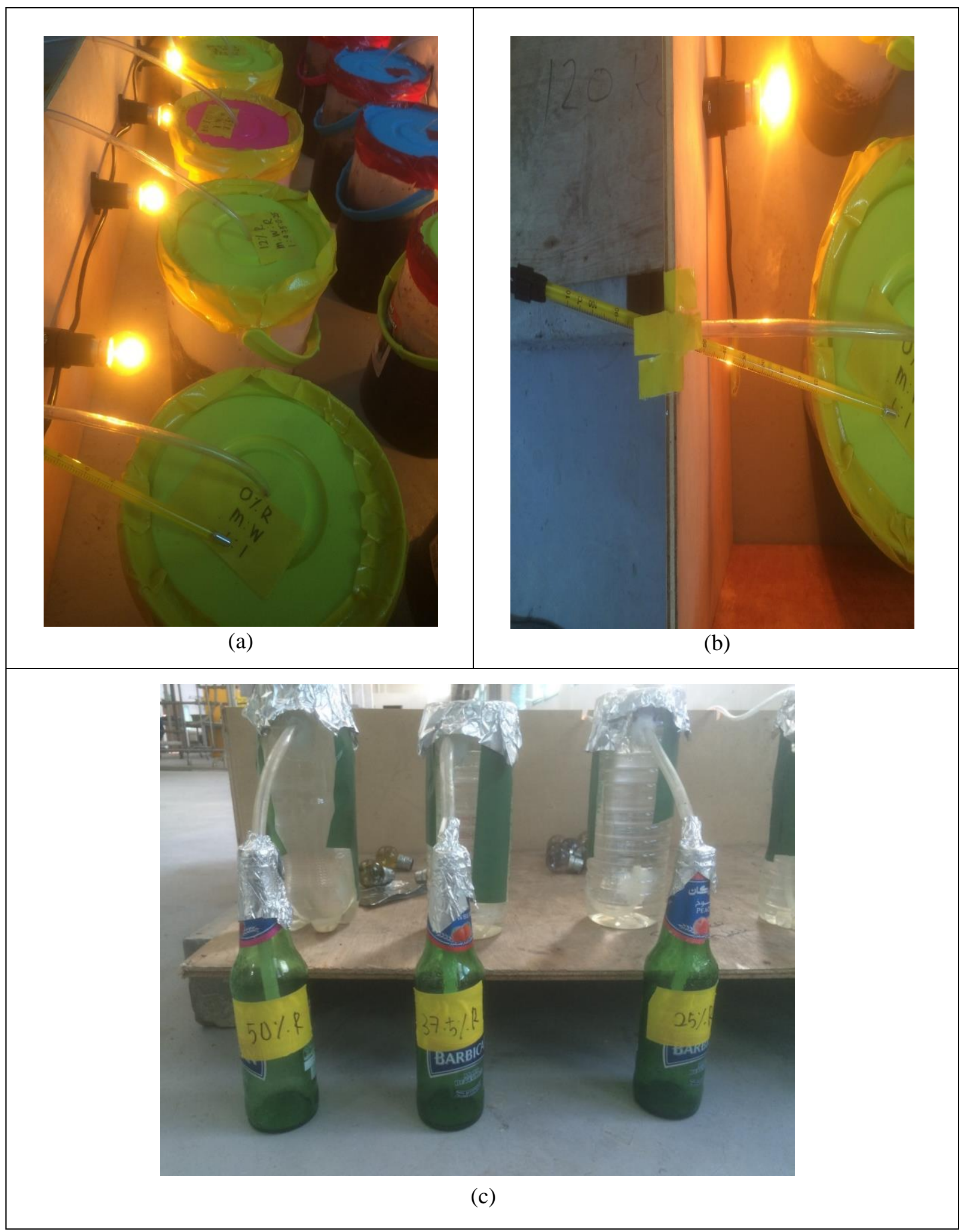

Figure 2: (a) Anaerobic digester uses lightbulb as a source of heat

(b) Thermometer was used to measure the temperature of the anaerbic digester

(c) The biogas collector for 3 different amount of rumen 


\section{Results and Discussion}

The results shown in this section were presented by two different graphs. First graph presented the result collected from the existing biodigester and second graph presented the result collected from fabricated biodigester.

\subsection{Existing Biodigester Unit- 0\% Rumen Fluid (Control Variable)}

A total of $5 \mathrm{~kg}$ mixture of manure and water were loaded in the biodigester unit with ratio of cow manure to water of 1:0.25. Figure 3 shows the results of $0 \%$ of rumen fluid (M:W 1:0.25) with hydraulic retention time of 40 days.

From Figure 3, the maximum biogas produced after 40 days data collection is $282 \mathrm{~mL}$. Data presented in Figure 4.1 above shows that the biogas collected is increasing. In this experiment, the hydraulic retention time (HRT) or time that the feedstock was left in the biodigester, is kept constant, which is 40 days. After 40 days observation, there were still biogas produced showing that the feedstock has longer retention time for biogas production. As stated by Wilkie (2005), the amount of methane gas produced depends on the volatile solid present in the feedstock. Therefore, higher volatile solid in the feedstock tends to give larger production of biogas which was also having longer hydraulic retention time.

It could observed that the production of biogas started 13 days after the feedstock was loaded. And the production of biogas increase cumulatively during the experiment conducted.

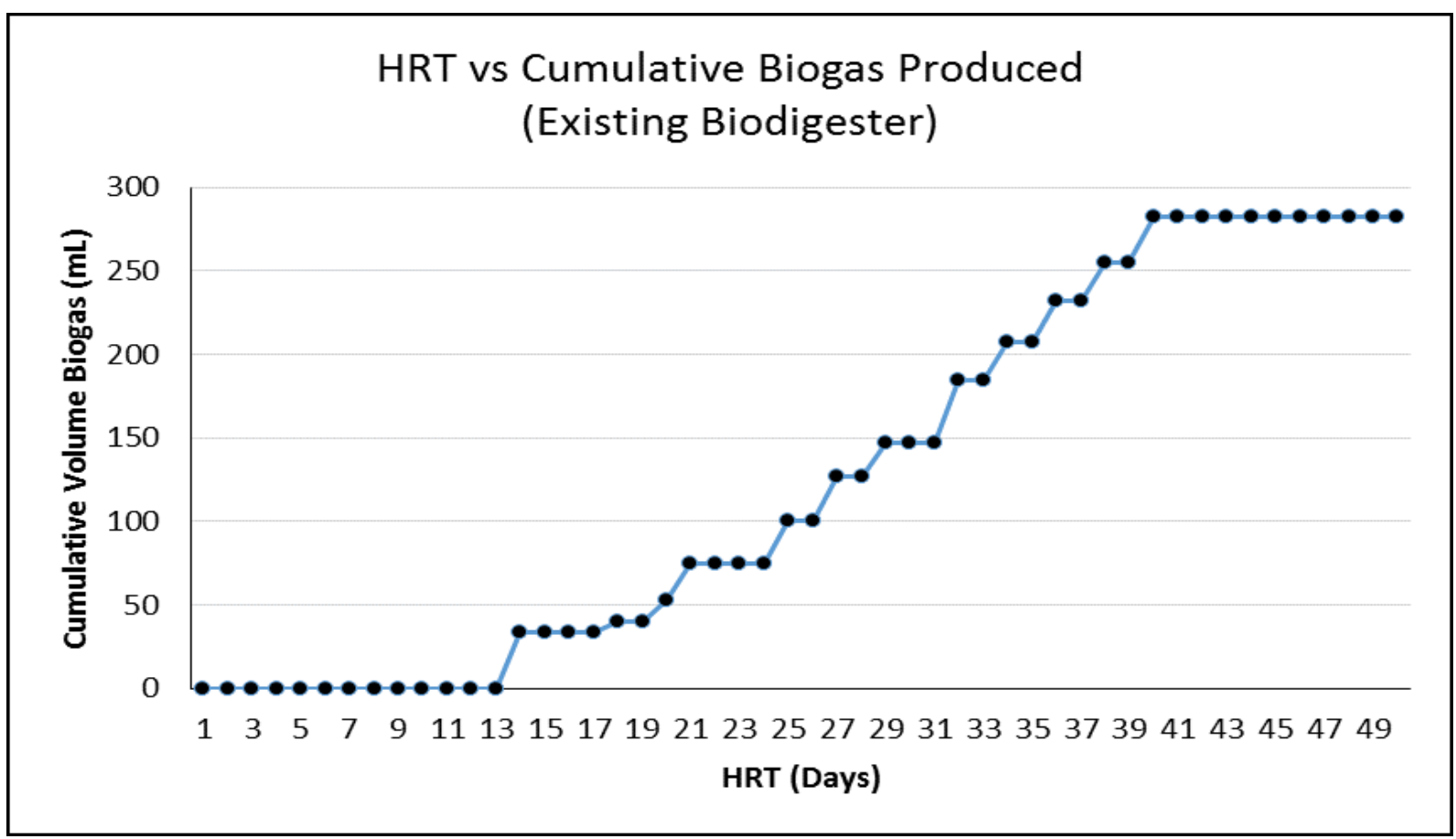

Figure 3: Cumulative biogas collected $(\mathrm{mL})$ versus hydraulic retention time (days). 


\subsection{Fabricated Biodigester (Manipulated Variable by Varying M:W:R Ratio)}

Each biodigester containing different amount of rumen fluid, which were $0 \%, 12.5 \%, 25 \%$, $37.5 \%$ and $50 \%$ rumen fluid, as shown in Figure 5 above. The cumulative biogas production of $0 \%$, $12.5 \%, 25 \%, 37.5 \%$ and $50 \%$ after 40 days observation are 19, 26, 33.5, 50.5 and $35.5 \mathrm{~mL}$ respectively. By comparing the biogas production, the highest biogas production is from $37.5 \%$ of rumen fluid followed by $50 \%$ rumen fluid, $25 \%$ rumen fluid, $12.5 \%$ rumen fluid and the lowest biogas production is $0 \%$ of rumen fluid. The results obtained are similar to the results obtained by Rabiu et al., (2014) where they found that at 25 days of experiment, the maximum biogas collected was from $37.5 \%$ rumen fluid.

From Figure 4, as the amount of rumen fluid increase from $0 \%$ to $37.5 \%$ in the biodigester, the production of biogas also increases. It is clearly shown that the influence of rumen fluid into the feedstock helps in increasing biogas production. The presence of rumen fluid provides inoculum for the bacteria in each steps of anaerobic digestion. Therefore, the amount of rumen fluid increase in the feedstock would increase the production of biogas.

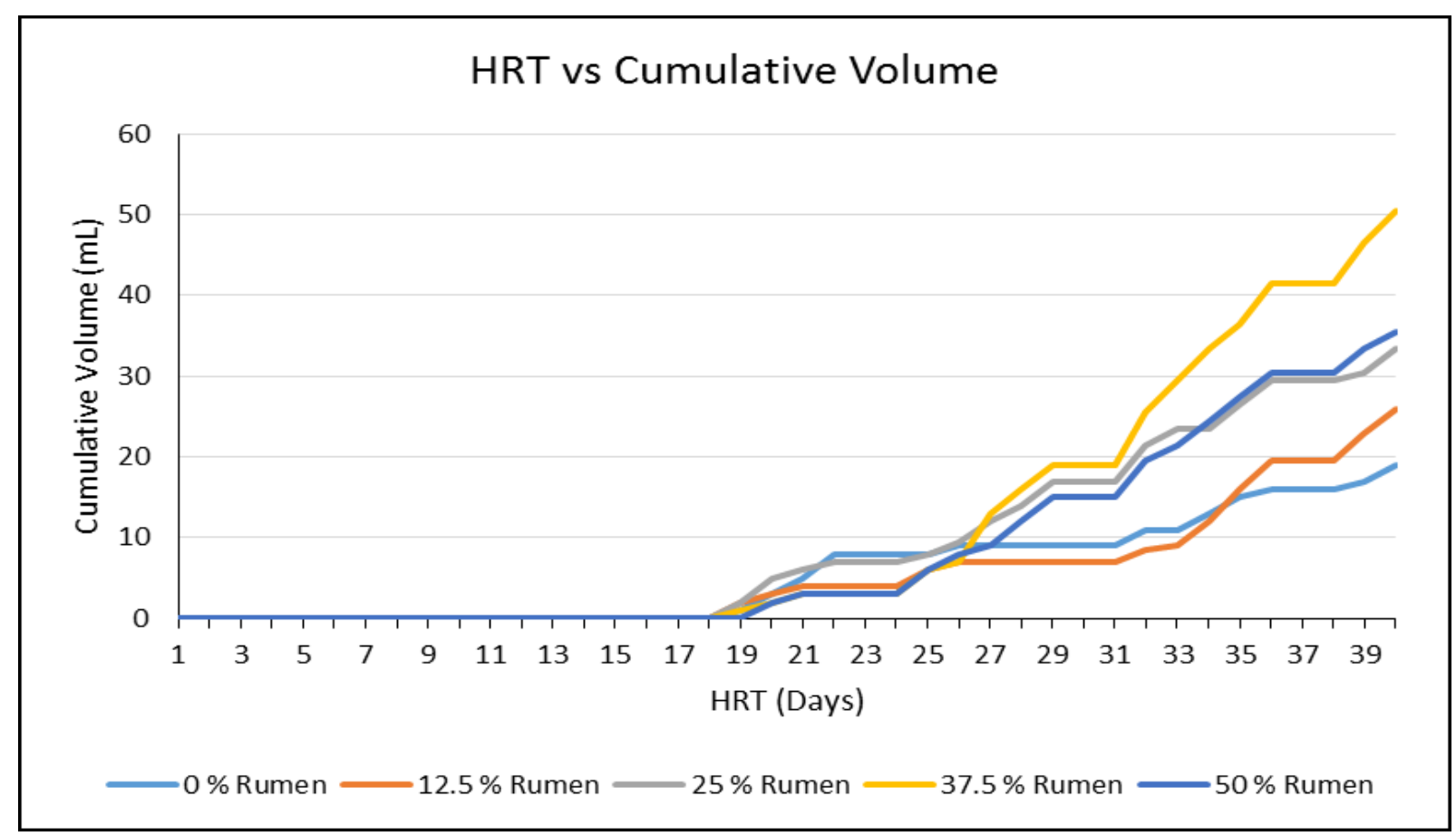

Figure 4: Biogas production from five different biodigester.

However, this does not apply to the biodigester containing $50 \%$ rumen fluid that showed the second highest biogas production. The biodigester is expected to have the highest biogas production compared to other biodigester that containing lower amount of rumen fluid. By examine the ratio of cow manure, water and rumen fluid in each biodigester, $50 \%$ rumen fluid biodigester is having 1:0:1 ratio (M:W:R). While $37.5 \%$ biodigester is having ratio of cow manure, water and rumen fluid of 1:0.25:0.75 (M:W:R). This means the difference between these two biodigester is the amount of water inserted to the biodigester.

According to Teda et. al. (2005), cow manure contain high amount of ammonia which can be very toxic for anaerobic bacteria and can inhibit the methane production. They also suggest that this problem can be solved by diluting the feedstock. By refering to the experiment, it shows that $50 \%$ rumen fluid biodigester contain high concentration of ammonia while $37.5 \%$ rumen fluid biodigester 
has lower concentration of ammonia by dilution with water. This ammonia problem has caused the 50 $\%$ rumen fluid biodigester to produce less biogas.

\section{Acknowledgements}

We would like to also show our gratitude to Universiti Malaysia Sarawak for providing us with the facilities required for our research.

\section{References}

[1] Borhanazard, H., Mekhilef, S., Saidur, R., \& Boroumandjazi, G. (2013). Potenial application of renewable energy for rural electrification in Malaysia. Renewable Energy. 59 pp 210-219.

[2] El-Mashad, H.M., Zeeman, G., Loon, W.K.P., Bot, G.P.A. \& Lettinga, G. (2004). Effect of temperature and temperature fluctauation on thermophilic anaerobic digestion of cattle manure. Bioresource Technology. 95, pp 191-201.

[3] Gerlach, F., Grieb, B. \& Zerger, U. (2013). Sustainable biogas production. Accessed on 18th November 2014. Retrieved from http://www.sustaingas.eu/fileadmin /sustaingas/documents /handbook SUSTAINGAS_handbook_EN.pdf .

[4] Natural Resources Defense Council (NRDC). (n.d.). Biogas energy. Accessed on 18th November 2014. Retrieved from http://www.nrdc.org/energy/renewables/biogas .asp.

[5] Rabiu, A., Yaakub, H., Liang, J.B., Samsudin, A.A. (2014). Enhancing biogas production rate of cattle manure using fluid of ruminants. Agriculture and Veterinary Science. 7(3), pp 25-28.

[6] Tada, C., Yang, Y., Hanaoka, T., Sonoda, A., Ooi, K. \& Sawayama, S. (2005). Effect of natural zeolite on methane production for anaerobic digestion of ammonium rich organic sludge. Bioresource technology, 96, 459.

[7] Wilkie, A.C. (2005). Anaerobic digestion of dairy manure: Design and Process Considerations. Natural Resource, Agriculture, and Engineering Service. NRAES (176), 301-312. 